\title{
I Congrés Música a la Llum. El patrimoni documental de les bandes de música
}

Elvira Asensi Silvestre ${ }^{1}$

\section{música a la llum

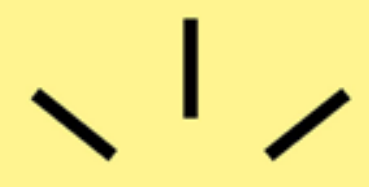$$
\text { M }
$$

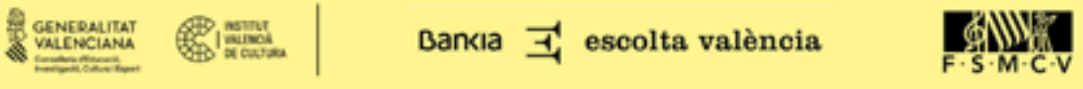

El Parlament Europeu i el Consell de la Unió Europea acordaren designar l'any 2018 com a Any Europeu del Patrimoni Cultural. L'objectiu era animar a més persones a descobrir i comprometre's amb el patrimoni cultural europeu i a reforçar el sentiment de pertinença a un espai comú. Així, amb el lema "El nostre patrimoni: on el passat es troba amb el futur", s'encoratjava als Estats membres a celebrar esdeveniments per posar-lo en valor.

Material, immaterial, natural o digital, el patrimoni cultural ens permet descobrir la nostra diversitat i alhora allò que ens uneix amb la resta. És per aquest valor universal perquè no s'ha d'abandonar, destruir, o deixar que es deteriorés. I és per aquesta raó, perquè cal trobar formes de gaudir-lo i protegir-lo. El Congrés Internacional“Música a la Llum. El patrimoni documental de les bandes de música" que es va celebrar a València del 13 a 15 de desembre de 2018 ben bé podria ser una d'aquestes iniciatives. L'objectiu d'aquest congrés, dirigit per Remigi Morant [professor de la Universitat de València i vicepresident de la Federació de Societats Musicals de la Comunitat Valenciana] i Jorge García, [cap de documentació i director adjunt de Música i Cultura Popular de l'Institut Valencià de Cultura], era contribuir a la valorització d'un dels senyals d'identitat valenciana com són les bandes de música. Un patrimoni que acaba de ser reconegut com a bé d'interès cultural pel govern valencià.

$1 \quad$ Universitat de València. elvira.asensi@uv.es 
Celebrat a l'Aula Magna de la Nau, seu de la Universitat de València, organitzat per I'Institut Valencià de Cultura, la Federació de Societats Musicals de la Comunitat Valenciana (FSMCV) i la Universitat de València, i patrocinat per Bankia, aquest congrés internacional ha aconseguit, a partir com veurem dels debats generats pels participants, que les bandes de música deixen de ser un "quotidià ignorat" per convertir-se en centre d'investigacions històriques i musicològiques que, tot plegat, contribueixen al camí de posada en valor que recentment s'ha encetat. La multiplicació de tesis doctorals i estudis parcials, el primer congrés sobre bandes organitzat per la Sociedad Española de Musicología [SEdeM] a Madrid el 2017 o l'aparició de la revista Estudios bandísticos, de l'Asociación Nacional de Directores de Banda, són senyals d'eixos canvis.

Cal tenir en compte, a més, que aquest congrés internacional s'emmarca en el projecte Música a la llum que va sorgir en 2016 i que té com a objectiu col.laborar amb les societats musicals per a la conservació, posada en valor i difusió del patrimoni cultural que s'ha anat reunint al seu voltant. Fomentar la investigació, descriure i donar a conèixer l'ingent material que custodien les bandes, esdevenen els principals eixos del projecte.

Atenent precisament a aquestes premisses, el congrés va establir diferents línies temàtiques com ara: la descripció dels fons musicals de les bandes i la seua visibilitat,la vinculació entre compositors i directors i els arxius de les societats musicals,les transcripcions en el repertori de les bandes, les bandes com a centres recol.lectors de la memòria musical d'un municipi, la circulació del repertori, els projectes de recuperació de la música per a banda oblidada,el patrimoni organològic, fotogràfic o documental a les societats musicals, etc.

Per portar a terme aquests temes, el congrés va comptar amb especialistes nacionals i internacionals que, amb les seues intervencions, van possibilitar la reflexió i el debat dels nombrosos aspectes que poden ser abordats en i des de les bandes. Així, Richard Scott Cohen [Ferris State University dels EEUU i vicepresident de The International Society for Research and Promotion of Wind] va dibuixar el panorama internacional del fenomen bandístic, posant en valor les bandes com a senyal d'identitat valenciana a l'estranger i com a model a seguir d'associacionisme musical. Apropant-se al repertori, Ramón Sobrino de la Universidad de Oviedo va rastrejar les influències musicals que tenen les composicions per a banda, tant d'arranjaments com originals. Un tema que es va completar amb la conferència del compositor, director i musicòleg valencià, Bernardo Adam Ferrero que focalitzà l'atenció en els compositors valencians. Atenent també a compositors valencians com són Chapí i Serrano, Cristóbal Soler (director i president de la Asociación Española de Directores de Orquesta] va donar les claus de la interpretació actual en les instrumentacions de les sarsueles dels citats compositors.

Quan es parla de repertori per a banda i de compositors valencians, no podia faltar l'anàlisi de l'obra de Carlos Llorens, La batalla de Inkerman [1855] que amb molta cura de detalls van realitzar els historiadors Salvador Astruells i Frederic Oriola. A més a més, van traure a la llum l'impacte social que aquesta peça va tindre al llarg de diferents contextos. Precisament, en la difusió internacional del repertori bandístic va focalitzar la seua conferència el pedagog, investigador i director de la Unió Musical de Torrent, Frank de Vuyst. La conferència de cloenda va córrer a càrrec del compositor i director José Rafael Pascual Vilaplana, actual director de la Banda Municipal de Barcelona i de la Banda Municipal de Bilbao, que amb el títol de: De Gabrielli a Johan de Meij: una aproximación histórica al repertorio de banda, va fer un recorregut pel repertori més destacat de composicions originals per a banda des del Barroc fins a l'actualitat. 
En un congrés que versa sobre el patrimoni de les bandes de música, calia comptar amb dos experts internacionals, André Granjo del Instituto de Etnomusicologia-Centro de Estudos em Música e Dança, Portugal i Sabina Benelli de l'Arxiu de l'orquestra del Teatro alla Scala de Milán; coordinadora del grup Broadcasting and Orchestra Libraries de la IAML, International Association of Music Libraries, Archives and Documentation Centres, perquè compartiren la seua experiència al capdavant d'iniciatives de conservació i posada en valor del patrimoni musical.

Les esmentades conferències van emmarcar diferents tandes de comunicacions amb la participació de musicòlegs, historiadors i músics que partint dels eixos dissenyats: Arxius [d'institucions públiques, privades i personals], context social de les bandes, fonografia i organologia, documentació, protecció i recuperació, i el popular i el culte en la formació del repertori bandístic, van traçar un panorama molt encoratjador de l'estat actual dels estudis en el món bandístic. Des de l'organologia de les peces originals o transcrites, fins a la conservació dels arxius històrics i musicals, passant per la contextualització històrica de les diferents societats musicals, tot plegat va posar de manifest les actuals corrents investigadores en la recerca bandística. De la mateixa manera es va debatre en una taula rodona la importància de què els arxius municipals col.laboren amb els de les societats musicals per tal de fer visible la riquesa del patrimoni musical de les bandes.

I no podia faltar en un congrés d'aquest tipus un concert ofert, en aquest ocasió, per la banda Unió Musical del Centre Històric dirigida per Vicente Gabarda amb la interpretació d'obres de Manuel Penella, José Manuel Izquierdo i José Serrano. La cloenda del congrés va venir de la mà d'una taula rodona on els participants en el Projecte de Música a la llum, informaven de les accions que estaven portant-se a terme al seu si i debatien amb els assistents la millor manera de què allò que s'estava traient a la llum arribés a totes les persones interessades.

Concloent direm que el congrés internacional va posar de manifest la riquesa d'estudis que sobre les bandes de música hi ha actualment, així com la quantitat de temes que es poden abordar rigorosament amb el patrimoni que roman als arxius amb què compten les societats musicals. Un patrimoni que és universal, que cal conservar i difondre i que amb projectes com el de Música a la llum té una oportunitat per fer-se visible i no romandre en una obscuritat on mai deuria haver anat. Tan de bo aquest siga el primer congrés de molts més que il.luminen el món de les bandes i que ens l'apropen a tothom. 